\title{
OPTIMUM DESIGN FOR TOURISM LINE BASED ON IMPROVED ANT COLONY SYSTEM ALGORITHM
}

\author{
Xu Mingle and You Xiaoming \\ ${ }^{1}$ Shanghai University of Engineering Science, Shanghai, China
}

\begin{abstract}
This paper proposed an available measure to find the shortest line of the tourism. Subjecting a lot of conditions, we aim at selecting to the best tourism line which will spend the less time in an economic way. To the practice travel problem, using $K$-means algorithm and ant colony optimization algorithm (ACO), we make a framework to solve the multi constraint combination optimization problem and design a real schedule to every feasible tourism line. In the end, we analyze the result and it is available to a traveler.
\end{abstract}

\section{KEYWORDS}

Ant colony optimization, $K$-means, path planning of travelling

\section{INTRODUCTION}

Tourism has become one of the factors to promote the development of the world economy. Along with the improvement of economy, in China, people's living standards have got a great advance. Meanwhile, there are an increasing number of people taking part in travel contributing to have a better body. In the activity, there is about a great deal of knowledges in deed. The tourism line is not only having an important impact on improving the quality of service but also having a profound influence about the scenic spot's sustainable development and the scenic spot, as we know, are the main places where develop activities and consume the tourism products.

This paper aims to solve the problem of tourism lines. With the help of K-means algorithm and ant colony optimization algorithm, we conclude a feasible measure based on a real problem, and the tourism line is not only convenient to traveler but help of improving the quality of serving to the related department.

\section{The Problem Of Tourism Line}

There are $2015 \mathrm{~A}$ Class touring scenic region published by National Tourism Administration of China, and a tourist loving driving a car by himself decide to travel according to the list. Every year, the tourist has no more than 30 days to travel and the time of travel is no more than four time. Every travel, there is no more than 15days. In view of one's prefer, there is the list of the least time in different view. In consideration of safety, he will only drive from seven o'clock in morning to seven o'clock in evening, and the time that he drives car is no more than eight hours every day. He will drive no more than three hours if he wants to visit all day and no more than five hours if he wants to visit half of a day. The speed is averagely ninety kilometers per hour at the super highway, and forty kilometers per hour at highway. The tourist plan to stay twenty four hours in provincial capital city at least to have time relax and the time is not used to visit. Every scenic region opens from morning eight o'clock to afternoon six o'clock. He prefers to drive on the super highway than on the highway. That is to say, he will drive on the super highway at first to get the nearby city of the view and go to the touring scenic region later. Problems as follows:

DOI: $10.5121 /$ ijmvsc.2016.7201 
Considering the information: the road and drive time from the nearby city to scenic view, the super highway of China and the relation of super highway of every provincial city, and the tourist's beginning point $\mathrm{Xi}$ an, plan a travelling line which includes every 5A Class touring scenic region, and the schedule including the start point, time of driving, distance of driving, view and so on.

\section{FRAMEWORK}

Indeed, this is a multi-constraint combination optimization problem and there is a great deal of time-complexity to solve it. Ant colony system algorithm having got a profound progress, which is inspired of the ant activities, is a better algorithm to solve this problem recently, [1]. According to distance, this paper classifies the cities and the staying time is time of visiting added time of driving car. As for the city having many scenic spots, we find the best travelling line by using ACS algorithm and we figure the time staying at the city based on the best travelling line. We will take a city having many scenic spots to a spot in this way. Considering the question, we compute time from a city to another city according to the distance of cities.

\subsection{Mathematical Model}

For solving the problem, as we knew, there are lots of restrict when a tourist have visited all of 5 A Class touring scenic region.

The result what we want to get is the least consume of the time, as follows:

$$
\begin{gathered}
\operatorname{Min} \sum_{i=1}^{n} T_{i}\left(i=1,2, \ldots, n \& 0<T_{i} \leq 30 \times 24\right) \\
T_{i}=\sum_{j=1}^{p} t_{i j}(0<p \leq 4) \\
t_{i j}=d_{i j 1}+d_{i j 2}+\ldots+d_{i j m} \quad(0<m \leq 15 \times 24) \\
d_{i j m}=d_{i j m 1}+d_{i j m 2}\left\{\begin{array}{r}
d_{i j m 1}+d_{i j m 2} \\
\text { if } \quad 4=d_{i j m 1}, d_{i j m 2} \leq 5 \\
\text { if } \quad 8=d_{i j m 1}, d i_{i j m 2} \leq 3 \\
0<d_{i j m 2} \leq 8 \\
d_{i j m 1} \in 8: 00-18: 00, d_{i j m 2} \in 7: 00-19: 00
\end{array}\right.
\end{gathered}
$$

Where $T_{i}$ in the object function (1) is the time for travelling in year $i$. Equation (2) is stand for the total time to travel which $t_{i j}$ is the time for time $\mathrm{j}$ travelling in year i. Equation (3) is representing all of the time for travelling every time in every year. While $d_{i j m}$ is the time to travelling the day $\mathrm{m}$ of the time $\mathrm{j}$ in year $\mathrm{i}$. Where $d_{i j m 1}$ is the time to visit the views and $d_{i j m 2}$ is the time for driving the car. The equation 5 is representing the restriction in everyday of travelling. 
International Journal of Managing Value and Supply Chains (IJMVSC) Vol. 7, No. 2, June 2016

\subsection{Clump Of The Figures Based On The Algorithm K-means}

$\mathrm{K}$-means is a classic algorithm based on distance, which adopts distance as the analogic criteria for evaluation, [2]. That is to say that the objects are more alike when the distance between them is shorter. There is helpful that considerate the compact and independent cluster as a final target, [3].

According to the scenic spot, at first, we take a city having a lot of views as a scenic spot on the basis of the distance with K-means algorithm. And in the same way, we take the time of visiting and driving car at all views of a city as the total time staying in a city. As for the city that has a lot of views, we try to find the best line for visiting all the cities, and take the time spending in the best line including the time to visit the views as the total time in the city. The result is presented in the table 1 .

There are 87 cities having scenic spot at all according to the table 1. In consideration of the tourist's plan that must spend 24hours in every provincial capital and there are 32 provincial capital, there are 119 city the tourist will be going to visit without overlooking the overlapping between partial provincial capital and cities with scenic spot. We number these cities and the start city is numbered 1 .

Algorithm 1 shows the framework of K-means [4]. The result is presented in Fig1.

\begin{tabular}{|l|}
\hline Algorithm 1: Clumping \\
\hline 1: select 13 centroid $L_{i}\left(C_{i}, Z_{i}\right)$ \\
\hline 2: count the distance $D_{i}$ from the rest of cities $c_{i}{ }^{\text {to centroid }} L_{i}$, and clump \\
according to every centroid based on the shortest distance \\
\hline 3: update every centroid of every class \\
\hline 4: return to process 2 if there is change \\
\hline
\end{tabular}

Table 1. Clumping of cities

\begin{tabular}{|l|l|l|l|l|l|}
\hline number & city1 & city2 & city3 & city4 & city5 \\
\hline 1 & Tibet & & & & \\
\hline 2 & Heilongjiang & & & & \\
\hline 3 & Xinjiang & & & & \\
\hline 4 & Sichuan & Yunnan & & & \\
\hline 5 & Chongqing & Guizhou & & & \\
\hline 6 & Hainan & Guangxi & & & \\
\hline 7 & Guangdong & Hunan & & & \\
\hline 8 & Henan & Shandong & & & \\
\hline 9 & Jilin & Liaoning & & & \\
\hline 10 & Fujian & Jiangxi & Hubei & & \\
\hline 11 & Gansu & Shanxi & Qinghai & Ningxia & \\
\hline 12 & Jiangsu & Shanghai & Zhejiang & Anhui & \\
\hline 13 & Nei Monggol & Shanxi & Hebei & Beijing & Tianjin \\
\hline
\end{tabular}




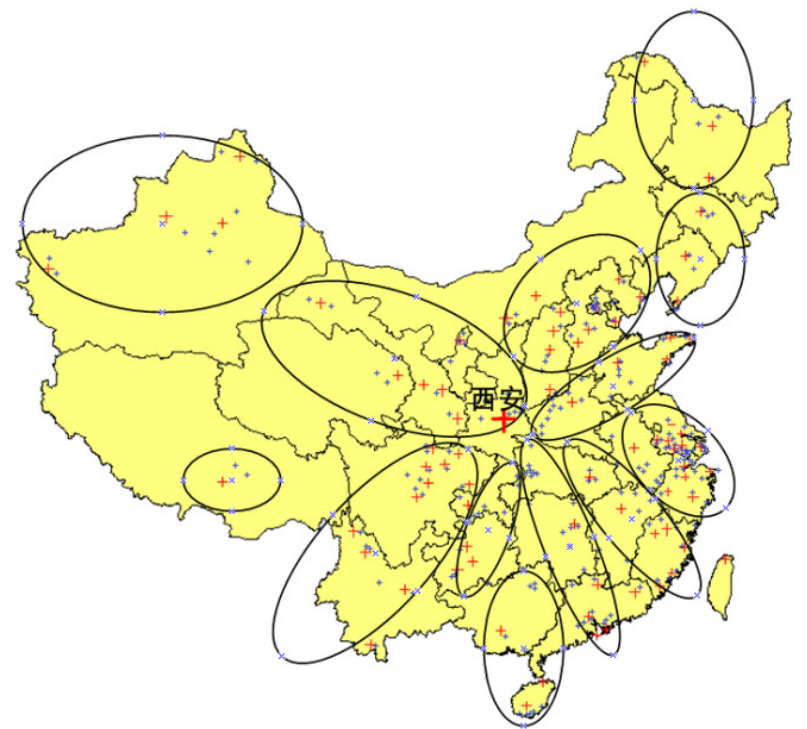

Fig. 1 clumping map

There are 87 cities having scenic spot at all according to the table 1 . In consideration of the tourist's plan that must spend 24hours in every provincial capital and there are 32 provincial capital, there are 119 city the tourist will be going to visit without overlooking the overlapping between partial provincial capital and cities with scenic spot. We number these cities and the start city is numbered 1.

\subsection{Improved Ant Colony Algorithm}

Ant colony system algorithm, which is enlightened from the activities of ant which look up the food in the real world, is a metaheuristics,[5]. The ant population in the natural world is not only able to find the shortest road form their nest to the food, but find the new road when the environment has changed. In consideration of the drawbacks of the traditional ACS algorithm, we adopt the improved ant colony system (GACS) based on chaotic which is able to improve the diversity of solution for it uses logistic mapping, and 3-opt local search which can improve the accuracy of the solution,[5][6].

The ACS was successfully applied on the travel sale problem (TSP) at first,[7]. In the problem, there is a group of cities and we are required to find a shortest circle road, which visits every city only once expecting the starting point. $d_{i j}$ is the distance from city $\mathrm{i}$ to city $\mathrm{j}$, but in view of the realistic condition and object function of this paper's problem, we take the time from city i to city $\mathrm{j}$ as $d_{i j}$ and the time is counted with supposing that the tourist drives car with the speed of 90 kilometers in the super way and with the speed of 40 kilometer in the highway. We create a matrix of $d_{i j}$ basing on the clump of the figures.

When ant is selecting the next city, it will select the higher pheromone road in accordance of probability. That is to say that it is a random process when an ant selects the next road. According to Dorigo and Stülzle, [8] the probability from city i to city $\mathrm{j}$ is defined as follows: 


$$
j=\left\{\begin{array}{cc}
\arg \max \left\{\left[\tau_{i j}(\mathrm{t})\right]\left[\eta_{i j}(\mathrm{t})\right]^{\beta}\right\}, & q \leq q_{0} \\
J\left(p_{i j}^{k}\right), & q>q_{0}
\end{array}\right.
$$

Where $\tau_{i j}(t)$ is the existing pheromone trail between the city i and city $\mathrm{j}$ in the time $\mathrm{t}, \eta_{i j}(t)$ is the heuristic information on the path from city i to city $\mathrm{j}$. Parameter $\alpha$ determine the relative influence of the pheromone trail and the parameter $\beta$ determine the relative influence of the heuristic information. Where $q$ is a random figure between 0 and 1 , and $0<q_{0}<1$ is a certain figure based on experience. Before the ant k selects the next city, it will create a random figure, and then compare the figure $q$ and $q_{0}$. If $q \leq q_{0}$, the ant $\mathrm{k}$ will select the next city according to the equation (6), and if $q>q_{0}$, according to the equation (7):

$$
p_{i j}^{k}=\frac{\left[\tau_{i j}\right]^{\alpha}\left[\eta_{i j}\right]^{\beta}}{\sum_{l \in N_{i}^{k}}\left[\tau_{i j}\right]^{\alpha}\left[\eta_{i j}\right]^{\beta}}
$$

Where $\eta_{i j}=\frac{1}{d_{i j}}$, and $N_{i}^{k}$ is the assemblage of available cities.

After ant $\mathrm{k}$ arrives at city $\mathrm{j}$ from city $\mathrm{i}$ in this algorithm, the amount of pheromone will be updated in accordance in the rule. In the end, basing on the logistic mapping algorithm, we will improve the result from ACS algorithm based on 3-opt algorithm. The rules are as follows:

$$
\begin{gathered}
x_{k+1}=\mu\left(1-x_{k}\right), \mathrm{k}=0,1,2, \ldots ; x_{0} \in[0,1] \mu \in(3,4] \\
\tau_{i j}(t+1)=(1-\varphi) \tau_{i j}(t)+\varphi \Delta \tau_{i j}(t)+q x_{i j} \\
\Delta \tau_{i j}=\sum_{k=1}^{n} \Delta \tau_{i j}{ }^{k}
\end{gathered}
$$

Where $\varphi$ is a variable constant, and $\varphi \in(0,1)$. Where $\Delta \tau_{i j}(\mathrm{t})$ is the amount of pheromone released by ant $\mathrm{k}$ when it gets to the city $\mathrm{j}$ from city $\mathrm{i}$. The rule of updating the pheromone is subjected to equation (11):

$$
\Delta \tau_{i j}{ }^{k}=\left\{\begin{array}{cc}
\frac{1}{L_{k}}, & \operatorname{arc}(\mathrm{i}, \mathrm{j}) \text { belong to best loop } \\
0, & \text { otherwise }
\end{array}\right.
$$

Where $Q$ is the amount of the pheromone, and $L_{k}$ is representing the time when the tourist visits the all cities. If $L_{k}$ is smaller than 7.5 or is equal to 7.5 , this line is a valid result. Otherwise, we will renew the clump according to the algorithm K-means.

Algorithm 2 shows the framework of improved ant colony algorithm. 
International Journal of Managing Value and Supply Chains (IJMVSC) Vol. 7, No. 2, June 2016

\begin{tabular}{|l|}
\hline Algorithm 2 improved ant colony algorithm based on 3-opt local search and chaotic \\
\hline $\begin{array}{l}\text { Step1: according to results of clumping, add Xi' an to every class, count the distance } \\
\text { of cities and transform these into time matrix }\end{array}$ \\
\hline Step2: initialize parameter iteration $i=0, \alpha, \beta, q_{0}, \eta_{i j}$, and initialize pheromone trails \\
\hline Step3: according to equation (8), initialize $x_{k}$ \\
\hline $\begin{array}{l}\text { Step4: put the starting point in the tabu list, select next city in accordance with } \\
\text { equation (6), and then put the city j into the tabu list }\end{array}$ \\
\hline $\begin{array}{l}\text { Step5: return Step3 until ant k find a circle load and count the road , then optimize } \\
\text { result based on 3-opt local search }\end{array}$ \\
\hline Step6: update pheromone over the selecting road according to equation (9) \\
\hline Step7: iteration $i=i+1$ \\
\hline $\begin{array}{l}\text { Step8: if } i<i_{\max }, \text { or the change of the result is big, or the change is little but , return } \\
\text { step1 and empty tabu list }\end{array}$ \\
\hline Step9: if $i=i_{\max }$ and the change is little, and, output the result \\
\hline
\end{tabular}

\section{Computational Results}

In order to investigate the performance of our algorithm, a series of experience have been carried out. The last result is that the tourist will at least spend nine years and 21 days to visit everyplace of 201 5A Class touring scenic region. The detail is presented in the table 2.

Table 2. Plan of visiting in 10 years

\begin{tabular}{|l|l|}
\hline & \multicolumn{1}{|c|}{ first year ( 30 days ) } \\
\hline first & $\begin{array}{l}\text { Xi'an, Jiuquan, Jiayuguan, Xining, Lanzhou, Tianshui, Pingliang, Xi'an } \\
\text { (11days) }\end{array}$ \\
\hline second & Xi'an, Zhangjiajie, Yueyang, Changsha, Hengyang, Xi'an (10 days) \\
\hline third & Xi'an, Nanning,Sanya, Haikou, Xi'an (9 days) \\
\hline & second year (29 days) \\
\hline first & Xi'an, Kashen, Aletai, Xi'an (15 days) \\
\hline second & Xi'an, Yili, Wulumuqi, Xi'an (14 days) \\
\hline first & third year (26 days) \\
\hline Second & $\begin{array}{l}\text { Xi'an, Jincheng, Xinzhou, Jinzhong, Shijiazhuang, Baoding, Xi'an (11 days) } \\
\text { Xi'an (15 days) }\end{array}$ \\
\hline first & $\begin{array}{l}\text { Xi'an, Beijing, Tianjin, Qinhuangdao, Chengde, Huhehaote, Eeduosi,Xi'an (15 } \\
\text { days) }\end{array}$ \\
\hline second & Xi'an, Dalian, Shenyang, Changchun, Xi'an (13 days) \\
\hline & fifth year (27 days) \\
\hline first & Xi'an, Wudalianci, Yichun, Haerbin, Xi'an (13 days) \\
\hline second & $\begin{array}{l}\text { Xi'an. Ji'an, Ganzhou, Longyan, Xiamen, Fuzhou, Ningde, Nanping, Sanming, } \\
\text { Xi'an (14 days) }\end{array}$ \\
\hline & sixth year (27 days) \\
\hline first & $\begin{array}{l}\text { Xi'an, Shangrao, Jingdezhen, Jiujiang, Wuhan, Yichan, Enshi, Shiyan, } \\
\text { Xi'an(14 days) }\end{array}$ \\
\hline second & Xi'an, Qingdao, Weifang, Yantai, Weihai, Jinan, Tai'an, Jining, Xi'an(13 days) \\
\hline
\end{tabular}


International Journal of Managing Value and Supply Chains (IJMVSC) Vol. 7, No. 2, June 2016

\begin{tabular}{|l|l|}
\hline & seventh year (25 days) \\
\hline first & $\begin{array}{l}\text { Xi'an, Luoyang, Jiaozuo, Zhengzhou, Anyang, Pingdingshan, Nanyang, } \\
\text { Xi'an(11 days) }\end{array}$ \\
\hline second & Xi'an, Chongqing, Bijie, Anshun, Xi'an (14 days) \\
\hline & eigth year (25 days) \\
\hline first & Xi'an, Quzhou, Huangshan, Hanzhou, Shaoxing, Xi'an(13 days) \\
\hline second & $\begin{array}{l}\text { Xi'an, Shanghai, Ningbo, Zhoushan, Nanjing, Liu'an, Anqing, Chizhou, } \\
\text { Fuyang, Xi'an(12 days) }\end{array}$ \\
\hline first & $\begin{array}{l}\text { Xinth year (26 days) } \\
\text { Xi'an(13days) }\end{array}$ \\
\hline second & Xi'an, Mianyang, Chengdu, A'ba, Jinghong, Xi'an (13 days) \\
\hline & tenth year (20 days) \\
\hline first & Xi'an, Lasha, Xi'an(10 days) \\
\hline second & $\begin{array}{l}\text { Xi'an, Shaoguang, Meizhou, Shenzhen, Qingyuan, Guangzhou, Foshan, } \\
\text { Xi'an(10 days) }\end{array}$ \\
\hline
\end{tabular}

The table 3 is presenting the schedule of every day about starting point, time of drive car, the distance, the scenic region in the first time of first year.

Table 3. The schedule of first time in first year

\begin{tabular}{|l|l|l|l|l|}
\hline day & start & time of driving & distance & views \\
\hline Day1 & Xi'an & 8 & 720 & $/$ \\
\hline Day2 & & 4.5 & 405 & Crescent Lake \\
\hline \multirow{2}{*}{ Day3 } & & & & Crescent Lake \\
\cline { 2 - 5 } & Jiuquan & 0.2 & 20 & $\begin{array}{l}\text { Jiayuguan cultural relics scenic } \\
\text { spot }\end{array}$ \\
\hline Day4 & Jiayuguan & 6.2 & 560 & Ta'er temple \\
\hline Day5 & Xining & 2.4 & 219 & $/$ \\
\hline Day6 & Lanzhou & 3.4 & 307 & $\begin{array}{l}\text { Tianshui Maiji Mountain } \\
\text { Scenic Area }\end{array}$ \\
\hline \multirow{2}{*}{ Day7 } & Tianshui & 2.5 & 230 & Kongtong mountain \\
\cline { 2 - 5 } & & & & Kongtong mountain \\
\hline Day8 & Pingliang & 4.7 & 426 & West China Film Studio \\
\hline Day9 & & & & West China Film Studio \\
\hline Day10 & Yinchuan & 8 & 720 & $/$ \\
\hline Day11 & & 0.2 & 18 & $/$ \\
\hline
\end{tabular}

\section{CONCLUSION ANd Future WORKS}

The schedule of tourism is a problem that is relevant to much knowledge. In this paper, we have proposed a method to design a visiting line of visiting all of the scenic regions, and we have got an appropriate schedule. But as we know, there are many influence factors which may be having interrelationship, and in the real world, there are many factors which are difficult to quantify or describe. In the future, we will combine the analytical way of quality with quantity. Besides, in this paper, we don't think of other means from a city to a city, for instance, by train, by plane and only think of the Xi' an as the starting point. We will also think of these aspects in the future work. 
International Journal of Managing Value and Supply Chains (IJMVSC) Vol. 7, No. 2, June 2016

\section{ACKNOWLEDGEMENTS}

The authors gratefully acknowledge the support of Innovation Program of Shanghai Municipal Education Commission (Grant No.12ZZ185), Natural Science Foundation of China (Grant No.61075115), Foundation of No. k201502007. Xiao-Ming You is corresponding author.

\section{REFERENCES}

[1]. Xiong, L. and S. Zengqi, Status and development of optimal design for fuzzy control system based on computational intelligence algorithms. Control and Decision, 2007. 22(9): p. 961-966.

[2]. Zhangjianping, L., Application in Cluster's Analysis Is Analyzed in Children Development Period. Application Research of Computers, 2007. 24(5): p. 166-168.

[3]. Lishiwei, W., Approach of Web clustering based on hybrid particle swarm optimization model. Application Research of Computers, 2010. 27(9).

[4]. Duanbaibin, W., Yuxiufen, Development on ant colony algorithm theory and its application. Con trol and D ecision, 2007. 9(2): p. 98-102.

[5]. Xuhongli, Q., Yunxiong, New ant colony optimization algorithm based on logistic chaotic image to resolve VRP problem. Application Research of Computers, 2012. 29(6): p. 2058-2060.

[6]. Lvjinqiu, Y., Liushen, Improved Ant Colony Algorithm Based on $\alpha$-nearest. Computer Engineering, 2015. 41(2): p. 184-188.

[7]. Dorigo, M., Gambardella, Luca Maria, Ant colony system: a cooperative learning approach to the traveling salesman problem. Evolutionary Computation, IEEE Transactions on, 1997. 1(1): p. 53-66.

[8]. Dorigo, M., V. Maniezzo, and A. Colorni, Ant system: optimization by a colony of cooperating agents. Systems, Man, and Cybernetics, Part B: Cybernetics, IEEE Transactions on, 1996. 26(1): p. $29-41$. 